\title{
Enhancing quality and safety in clinical teaching: Statewide live continuing education program for adjunct clinical nursing faculty
}

\author{
Kimberly N. Silver Dunker*1, Karen Manning ${ }^{2}$ \\ ${ }^{1}$ Worcester State University, Worcester, MA, United States \\ ${ }^{2}$ Laboure College, Boston, MA, United States
}

Received: January 24, 2018

DOI: $10.5430 /$ jnep.v8n7p78

\author{
Accepted: January 30, 2018 \\ Online Published: March 9, 2018 \\ URL: https://doi.org/10.5430/jnep.v8n7p78
}

\begin{abstract}
The nursing faculty shortage is being filled by adjunct clinical faculty with no classroom teaching experience. These novice faculty members must undergo a socialization and orientation process (onboarding), when transitioning into the academic environment. To support orientation, the Live Continuing Education Program for Adjunct Clinical Nursing Faculty (LCEPACNF), a competency-based 4.0-hour continuing education unit program for novice clinical faculty was used. In this study, the LCEP-ACNF was tested in a statewide sample of clinical faculty. For this mixed-methods study a convenience sample of faculty members $(\mathrm{N}=312)$ from all nursing programs in one northeast state was recruited. All 312 participants completed pretest competency-based evaluation and a demographics sheet. Participants' $(\mathrm{N}=312 ; \mathrm{n}=162)$ posttest scores were significantly higher than their pretest scores $(\mathrm{Z}=11.10, p<.01)$. Eight interviews were conducted and the themes emerged were, communication with other faculty members on clinical teaching, orientation strategies, student evaluation and feedback strategies, and mentorship issues for novice clinical faculty. Evaluation results for the LCEP-ACNF were overall positive, including the need for more continuing education offerings, mentorship, and teaching strategies. The results suggest an increased need for clinical faculty development and orientation, a need for developing the clinical coordinator role and mentorship for all novice clinical faculty. Lastly, the LCEP-ACNF should be offered twice a year, regionally and nationally.
\end{abstract}

Key Words: Nursing faculty, Orientation, Mentorship, Competencies, QSEN

\section{INTRODUCTION}

Insufficient number of nursing faculty is the primary reason many qualified applicants are denied admission to nursing programs. ${ }^{[1-4]}$ Furthermore, the American Association of Colleges of Nursing, ${ }^{[1]}$ states there is a faculty shortage. The current faculty vacancy rate nationally is 7.1 percent. The faculty shortage is also supported in the literature as vacancy rates continue to grow. ${ }^{[5,6]}$ In the midst of the rising faculty shortage, insufficient number of educators who have advanced degrees or are doctorally prepared are available to teach. ${ }^{[7]}$ To balance the dwindling number of nursing faculty and increasing student enrollment, nursing programs have to increasingly rely on clinically expert nurses who are novice educators as adjunct clinical instructors. ${ }^{[1,8,9]}$ Because the clinical teaching component is a critical element in undergraduate nursing programs providing adjunct clinical faculty with the tools they need to be successful is crucial. The literature stresses that using expert registered nurses to assume

*Correspondence: Kimberly N. Silver Dunker; Email: kdunker@ worcester.edu; Address: Worcester State University, Worcester, MA, United States. 
the role of an adjunct nursing clinical instructor is challenging. As they transition from clinical expert bedside nurse to novice nurse educator, they must be provided with support and orientation in this new role. ${ }^{[10-13]}$ Support through faculty development is noted to be associated with positive students and program outcomes. ${ }^{[14]}$

\subsection{Background \& significance}

\subsubsection{Theoretical framework}

The conceptual framework chosen for this study was the novice to expert model. ${ }^{[15]}$ The framework defines a process that nursing clinical faculty follow to become experts in their new role of clinical teaching. Moreover, this framework focuses on expert bedside nurses who move from practice to academia resulting in novice clinical educators, where their accumulated knowledge, judgment, and skills no longer apply. ${ }^{[16]}$ They transition back into the role of a novice when in the field of education. ${ }^{[11,17]}$ Given the complexity of the nurse clinical educator role, novice clinical faculty members must be guided in the acquisition of skills to facilitate student learning. ${ }^{[11]}$ Furthermore, noted in the literature, mentorship is essential in the pathway to gaining this knowledge and skills as a new faculty member. ${ }^{[18]}$

\subsubsection{Orientation \& onboarding for the nurse educator role}

To prepare nurses for the role of nurse educator and ensure that they can successfully teach and mentor students, they must be formally prepared. ${ }^{[19-22]}$ One important aspect of this preparation is ensuring that these new educators can incorporate evidence-based teaching strategies and practices into the clinical learning environment, thus preparing new nursing school graduates to meet the IOM's 2020 goal of basing $90 \%$ of clinical decisions on the best available evidence to improve patient outcomes. ${ }^{[23-25]}$ Building faculty capacity to promote student achievement of desired learning $^{\text {[24] }}$ requires an onboarding and orientation program based on evidenced-based teaching practice and aligned with competencies. $^{[26]}$

Onboarding is more than orienting new employees to a new role and/or organization; it is a process of supporting these employees and facilitating their adjustment to their new position in the organization. ${ }^{[27]}$ Quality onboarding provides all the necessary information needed through open communication, explanation of resources, and individualized training. [27-29]

An effective onboarding program improves not only the newcomer's adjustment process, but also organizational effectiveness by promoting positive employee attitudes, improving job performance, and decreasing turnover. ${ }^{\text {27, 29,30] }}$

Published by Sciedu Press
Formalized orientation is an evidence-based strategy that can be used to prepare and socialize novice nurse educators into the academic role, increasing job satisfaction and retention. ${ }^{[31]}$ Indeed, employee satisfaction has been documented to greatly improve both job performance and retention. ${ }^{[32,33]}$ Ultimately satisfied employees will be happy in their position and want to stay. The primary goal of successful onboarding and orientation is to increase faculty retention, as a strategy to address the nursing faculty shortage.

Although clinical faculty satisfaction has not been correlated with patient outcomes, clinical nursing satisfaction has been related to patient safety through key factors of retention and quality care. ${ }^{[34-37]}$ Furthermore, improving patient safety in clinical settings has been linked to changes in systems of care rather than focusing on individual errors. ${ }^{[38]}$ As recommended in the medical literature all clinical faculty must attain competency in quality improvement and patient safety. ${ }^{[39]}$ Healthcare and nursing care in general are influenced by the care culture of the ward or unit. ${ }^{[40]}$

Ultimately, developing and retaining clinical faculty is necessary to maintain stability of nursing schools to prepare tomorrow's professional nurses. ${ }^{[41,42]}$ To ensure a consistent link between nursing academics and practice, nursing competencies should be embedded within the onboarding and orientation program for new clinical faculty. These new faculty members as well as students, the academic institution, and health care organizations will benefit from enhanced learning experiences and improved clinical experiences as they work together to create a culture of safety and quality care.

\section{METHODS}

The Live Continuing Education Program for Adjunct Clinical Nursing faculty (LCEP-ACNF) was developed to orient new adjunct clinical nursing faculty to the nurse educator role. ${ }^{[43,44]}$ In order to evaluate the effectiveness of the LCEPACNF, the author piloted the LCEP-ACNF on line using pre-and posttest analysis. ${ }^{[45]}$ Following this evaluation, the program was converted to a live format, as a continuing education program, and was offered at three nursing schools to orient new clinical faculty. ${ }^{[43,44]}$ Because this program was successful at three nursing schools, the next phase was to offer the LCEP-ACNF at regional locations in the northeast. The purpose of this study was to evaluate the effectiveness of the LCEP-ACNF for a larger sample of nursing faculty with various levels of teaches experience across Massachusetts. The long-term goal is that our statewide results will serve as a catalyst for other states to adopt statewide clinical faculty orientation. 
Utilizing the Kirkpatrick ${ }^{[45]}(1998)$ model for program evaluation this study had three aims: (1) to assess the effectiveness of using modules to present the content of the LCEP-ACNF, (2) to evaluate LCEP-ACNF participants' knowledge by preand posttest scores, and (3) to evaluate the effectiveness by seeking feedback of those who attended the LCEP-ACNP by interviewing participants 6-8 weeks after the program.

\subsection{Design}

Data was collected during two periods to evaluate the was the effectiveness of the LCEP-ACNF. A correlational descriptive design was chosen to evaluate the program effectiveness collected through demographics and pre-and posttest information. Approximately six to eight weeks following the educational intervention qualitative descriptive data was collected using interviews.

\subsection{LCEP-ACNF}

The LCEP-ACNF ${ }^{[44,45]}$ was based on a triad of nursing competencies (a) NLN nurse educator competencies, ${ }^{[46]}$ (b) Quality and Safety in Nursing Education (QSEN) competencies, ${ }^{[47,48]}$ and (c) Massachusetts Nurse of the Future Nursing Core Competencies (NOFNCC) competencies. ${ }^{[49]}$ This program is delivered in eight lessons in modular format (see Table 1). ${ }^{[4]}$ The LCEP-ACNF was given as a 4-hour continuing education unit workshop that incorporated video vignettes power point presentations and live role playing to clarifying each learning module, with break-out sessions after each module for participants to discuss its content ${ }^{[45,50]}$ (see Table 1). The video vignettes, were designed to augment the lesson studied. They contain educator and student role playing through common scenarios which occur in the clinical setting. These videos help faculty to learn how to interact with and guide students to be successful in clinical experience/practicum.

\subsection{Sample and setting}

After this study was approved by the institutional review board at the University of Massachusetts Graduate of Nursing School, the LCEP-ACNF was presented to nurse faculty and leaders attending the Second Annual Massachusetts Healthcare Workforce Summit sponsored in the fall of 2015 by the Massachusetts Action Coalition (MAAC). At the summit, the program was presented as a way for schools of nursing to orient new adjunct clinical faculty to academic nursing education. The deans of six schools of nursing chose to host the LCEP-ACNF at a mutually convenient date, time, and location with ample parking for the participants of the workshop. Participants for each of the six 4-hour LCEP-ACNF workshops were invited through e-mails sent by the researcher to all summit attendees. The e-mails included a fact sheet and a link to a site where registrants used research electronic data capture (REDCap) software to complete a demographic questionnaire and pretest. Completing these documents was not a requirement for attending the workshop.

The workshops were hosted by the six nursing schools on their university or college campus. A classroom or auditorium, $\mathrm{AV}$ equipment, and parking were made available to all participants in the workshop. Although participants completed the pre-workshop information in either their office, home, or other location with a computer, the workshop was held live at one of the college campuses.

\subsection{Data collection}

At the start of each workshop, the first author reviewed the fact sheet with participants to restate the purpose of the program; its procedures; participants' rights to withdraw at any time, to decline participation without any effects on their employment, and the confidentiality of their information; as well as the risks and benefits of participating. The presenter also answered any questions. All faculty members who participated in the LCEP-ACNF completed the required continuing education evaluation to obtain contact hours. A pretest was created and designed for and used previously in phase one and two of this project. ${ }^{[44,45]}$ Reliability was established previously in two pilot studies. The pretest included 25 multiple choice knowledge, comprehension, and application level questions related to the module content in the LCEP-ACNF. The questions were used to assess participants baseline knowledge of clinical education content. This was created for the workshop and was previously utilized in a pilot study. ${ }^{[45]}$ Content validity for the pre/post-test was established through pilot testing of a convenience sample of 134 nurses. ${ }^{[45]}$ Furthermore, construct validity was conducted using a factor analysis analyzing each item question on the test. The data from these tests were collected using REDCap software. All data were exported to SPSS and kept on a secured research drive. All data forms were assigned a unique code letter and number with no names or other identifiers. Identifiers, including those on audio recordings, were destroyed after data analysis and study completion. All other research records will be maintained for 3 years following study completion and then destroyed.

Immediately after the workshop, participants evaluated the LCEP-ACNF using a 34-item continuing education evaluation form (see Table 2). The 25 closed-end items evaluated whether the objective of each module was met, with one open-ended item for overall comments about the program. Objective items were rated on 5-point Likert scale from 1 (strongly disagree) to 5 (strongly agree). Completing this form was required for participants to receive their contact 
hour certificate. Within 24 hours of attending the work- 162), and items evaluated. This posttest was the same test shop, all participants were sent a follow-up e-mail with the as the pretest. Participants were encouraged to complete the posttest, additional conference handouts and materials. Table 4 demonstrates pretest versus posttest scores $(\mathrm{N}=312 ; \mathrm{n}=$

Table 1. LCEP-ACNF objectives, competencies and vignettes

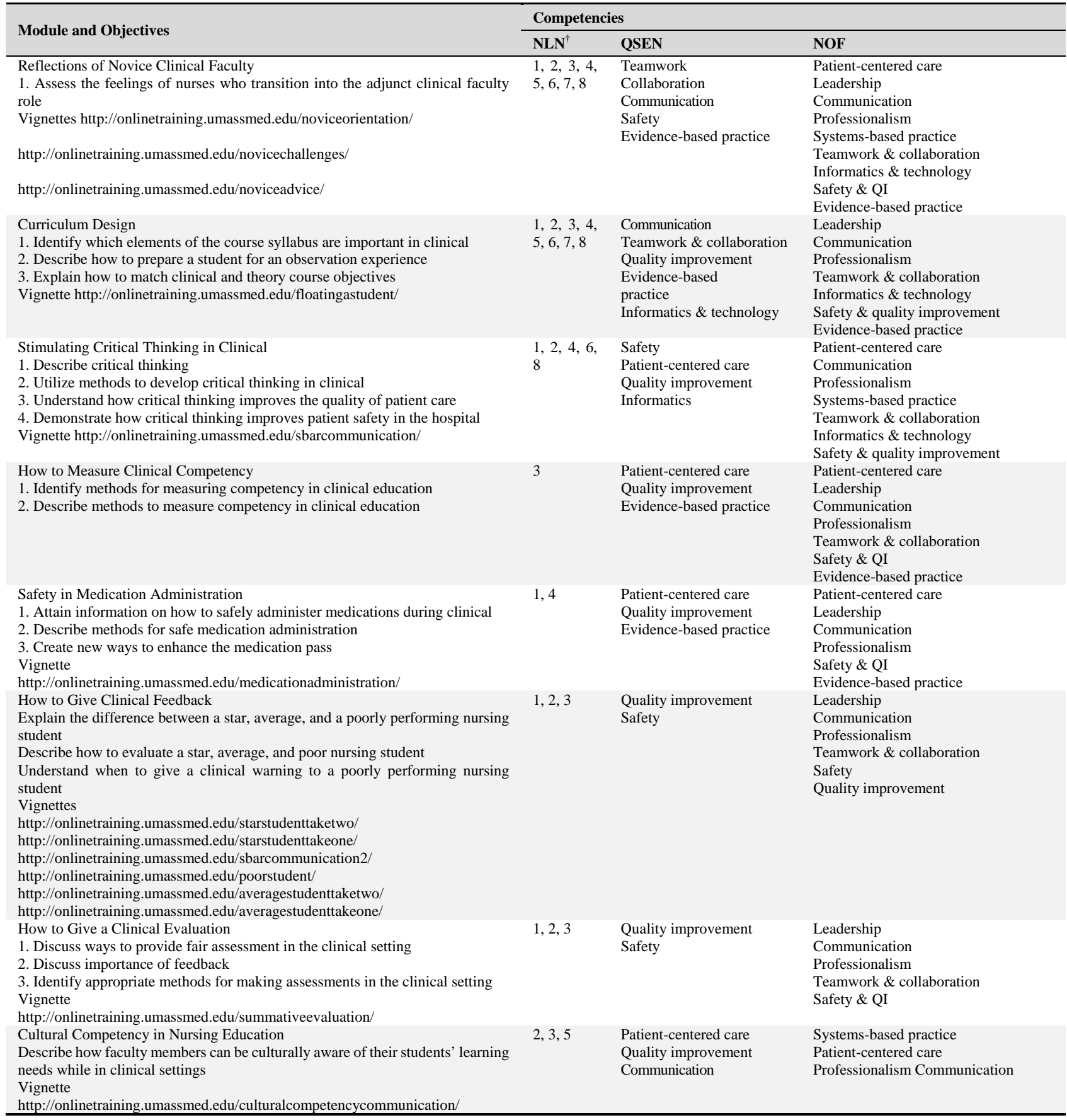

Note. NLN = National League of Nursing, Nurse Educator; QSEN = Quality and Safety Education for Nurses; NOF = Nurse of the Future; QI = Quality improvement

*All links to videos can be used by workshop participants. These videos are the property of Dr. Silver Dunker and are copyrighted. If videos are used, please notify Dr. Silver Dunker at kdunker@worcester.edu. Please give all credit to Dr. Silver Dunker

${ }^{\dagger}$ Numbers refer to the eight NLN competencies: 1) facilitate learning, 2) facilitate learner development and socialization, 3) use assessment and teaching strategies,

4) participate in curriculum design and evaluation of program outcomes, 5) function as a change agent and leader, 6) pursue continuous quality improvement in the nurse educator role,

7) engage in scholarship, and 8) function within the educational environment 
Table 2. Contact hour evaluation

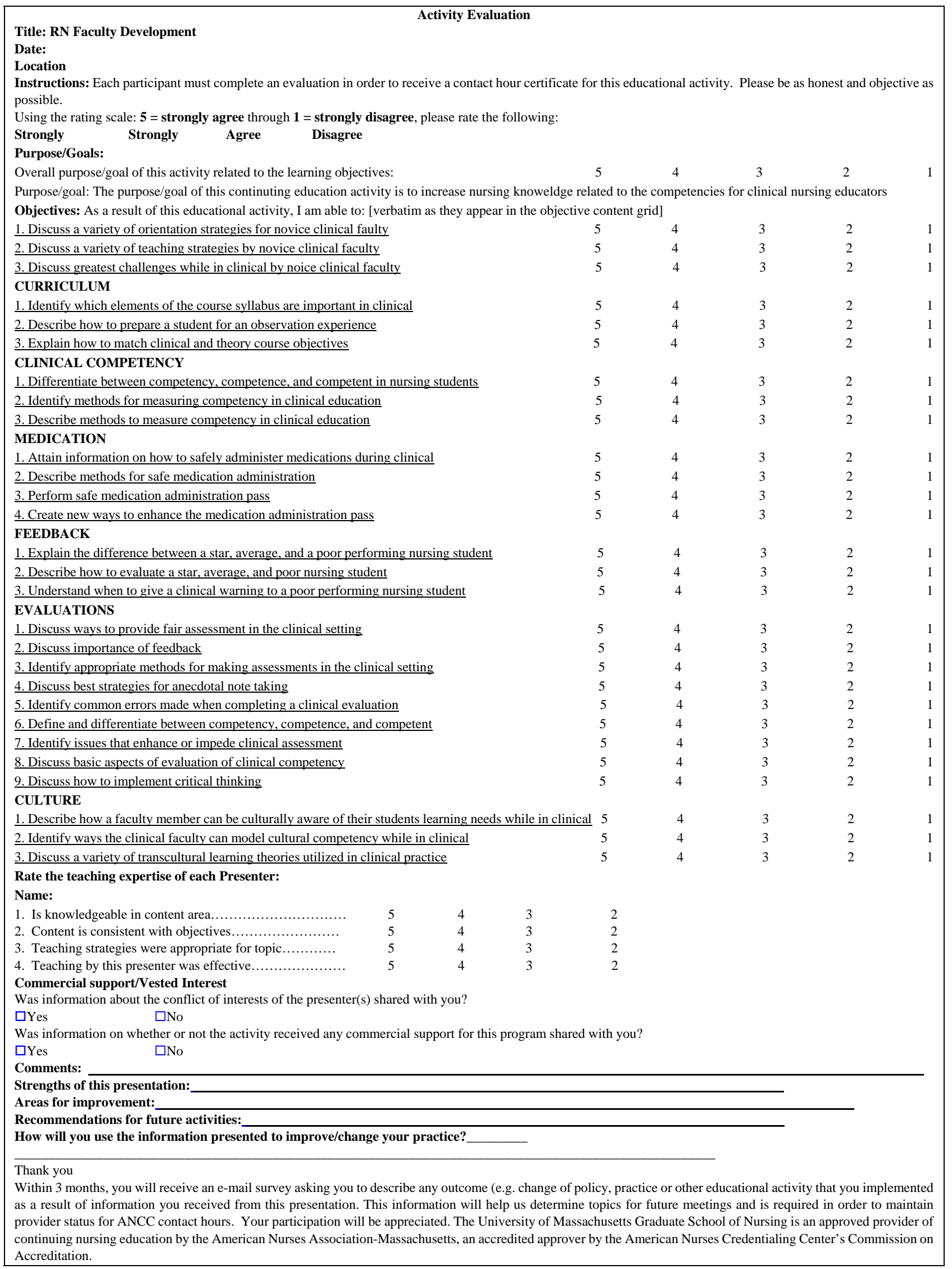


Six weeks after the program, all participants were contacted and invited to participate in 45- to 60-minute interview to discuss how the LCEP-ACNF impacted their clinical semester. Eight participants agreed to be interviewed for the follow-up evaluation. Seven were interviewed over the phone (lasting 45 minutes) and one was interviewed in person. At the beginning of each interview, participants' consent was obtained after clarifying that the interview would be recorded for transcription only, that all data would be destroyed after the data were analyzed and the results submitted for publication, and that participants could end the interview at any time. During and after each interview, the author made field notes on paper.

\subsection{Data analysis}

Demographic data were analyzed by descriptive statistics (means, standard deviations, frequency, and percentages). Differences in pre- and posttest outcomes by demographic characteristics were compared by $t$-test for the one continuous variable (age) and by chi-square test for the categorical variables (e.g., race, education level). All statistical analyses were conducted using SPSS.

Qualitative data from the open-ended responses on continuing education evaluation forms $(\mathrm{N}=312)$ and follow-up interviews $(n=8)$ were analyzed, interview audiotapes were transcribed verbatim by a transcriptionist. Transcripts were analyzed concurrently with interviews to determine when data were saturated and no further interviews were needed. Saturation occurred after four interviews. After each interview, the author listened to the audiotape at least two times. Once an interview was transcribed, the transcript was compared to the audiotape to assure accuracy. A thematic analysis was conducted evaluating the interview transcripts using a line-by-line coding process; key terms included orientation, mentoring, faculty needs, support, and strategies. All interviews were double coded and both researchers met to discuss and resolve findings of the interview. To ensure trustworthiness the researcher using bracketing of past information and knowledge about the clinical faculty orientation program in previous offerings. To do this another researcher participated in the data analysis who did not attend the faculty workshop nor did they have prior interaction with any participants in previous workshops. Lastly, field notes were taken during the interview to provide details regarding the participants voice changes and emotions.

\section{Results}

\subsection{Participant characteristics}

The sample of 312 participants was primarily female (97\%), white $(87.3 \%)$, and highly educated $(70 \%$ had at least a master's degree), with a mean (SD) age of 44 (4.5) years. The majority of participants were adjunct professors (52\%), worked as clinical faculty (73\%), and had worked as nurses for $<2$ years $(28 \%)$ or $>10$ years $(29 \%)$ (see Table 3$)$. Participants for this qualitative interview did not complete a demographic questionnaire. Of the participants five were faculty having taught 0-3 semesters, two were faculty members with less than five years of clinical experience and one faculty member was not a clinical teacher but a coordinator of multiple clinical faculty.

Table 3. Participants' demographic characteristics $(\mathrm{N}=312)$

\begin{tabular}{|c|c|c|c|}
\hline Characteristic & $n(\%)$ & Mean (SD) & Range \\
\hline Age, years & & $44.0(4.5)$ & $25-45$ \\
\hline \multicolumn{4}{|l|}{ Gender } \\
\hline Female & $298(95)$ & & \\
\hline Male & $8(2.5)$ & & \\
\hline Did not respond & $6(2.5)$ & & \\
\hline \multicolumn{4}{|l|}{ Race } \\
\hline White & $272(87)$ & & \\
\hline Black & $13(4)$ & & \\
\hline Other & $27(9)$ & & \\
\hline \multicolumn{4}{|l|}{ Employment } \\
\hline Full-time & 123 (39) & & \\
\hline Part-time & $28(9)$ & & \\
\hline Adjunct & $161(52)$ & & \\
\hline \multicolumn{4}{|l|}{ Education } \\
\hline BSN & $80(26)$ & & \\
\hline Master's degree & $198(64)$ & & \\
\hline $\mathrm{PhD}$ & $10(4)$ & & \\
\hline Doctorate of Nursing Practice & $8(2)$ & & \\
\hline Did not answer & $16(4)$ & & \\
\hline \multicolumn{4}{|l|}{ Nursing experience, years } \\
\hline $0-2$ & $87(28)$ & & \\
\hline $3-5$ & $67(22)$ & & \\
\hline $6-10$ & $64(21)$ & & \\
\hline$>10$ & $87(29)$ & & \\
\hline Did Not Answer & $7(4)$ & & \\
\hline \multicolumn{4}{|l|}{ Clinical Faculty } \\
\hline Yes & $229(73)$ & & \\
\hline No & $83(27)$ & & \\
\hline \multicolumn{4}{|l|}{ Program type taught in } \\
\hline Undergraduate (AD/BSN) & $202(65)$ & & \\
\hline Licensed Practical Nurse & 105(34) & & \\
\hline Graduate (Master’s degree) & $5(1)$ & & \\
\hline
\end{tabular}

\subsection{Pretest vs. posttest outcomes}

Participants' pretest and posttest scores did not differ significantly by any demographic variable except educational level. 
Master's degree-prepared participants had higher pretest/post test scores than those who were bachelor prepared $\left(\chi^{2}=8.09\right.$, $p=.05)$. Table 4 compares each item on the pre-and posttest using the McNemar Chi-square test to identify which items were significant in the score results. After individually analyzing each question on the pre/posttest the content areas, which faculty showed significant growth included: (1) safety with medication administration (2) sending student on observations during clinical (3) and clinical teaching related to course objectives. These areas are safety considerations for all clinical faculty and are essential items. Therefore, this growth demonstrates the LCEP-ACNF creates a faculty member who is a safer clinical faculty overall.

Most significant results were that the mean posttest scores as they were significantly higher than overall pretest scores (see Table 5), indicating that the LCEP-ACNP program improved participants' knowledge of all nursing competencies.

Table 4. Pretest versus posttest scores $(\mathrm{N}=312 ; \mathrm{n}=162)$

\begin{tabular}{|c|c|c|c|}
\hline Item & $\begin{array}{l}\text { McNemar } \\
\text { Chi-square (\# Answered Correct Pretest) }\end{array}$ & $\begin{array}{l}\text { McNemar } \\
\text { Chi-square (\# Answered Correct Posttest }\end{array}$ & $p$ \\
\hline 1 Syllabus I & 3 & 146 & .000 \\
\hline 3 Clinical Assignments & 140 & 153 & .523 \\
\hline 4 Nursing Skill Instruction & 96 & 127 & .597 \\
\hline 6 Nursing Care Map/Nursing Diagnosis & 67 & 98 & .342 \\
\hline 7 Clinical Observation I & 160 & 160 & .000 \\
\hline 8 Clinical Observation II & 123 & 152 & .002 \\
\hline 9 Syllabus II & 156 & 158 & .688 \\
\hline 10 Formative Evaluation I & 157 & 160 & 1.000 \\
\hline 12 Summative Evaluation II & 136 & 147 & .557 \\
\hline 13 Formative Evaluation II & 147 & 157 & .302 \\
\hline 14 Formative Evaluation III & 159 & 160 & 1.000 \\
\hline 15 Formative Evaluation IV & 6 & 150 & .000 \\
\hline 16 Medications II & 21 & 101 & .000 \\
\hline 17 Medications III & 156 & 160 & .688 \\
\hline 18 Medications IV & 107 & 130 & .576 \\
\hline 19 Medications V & 151 & 156 & 1.000 \\
\hline 20 Critical Thinking Post Conference & 20 & 60 & .182 \\
\hline 21 Critical Thinking Journal & 118 & 139 & .627 \\
\hline 23 Cultural Competency I & 25 & 76 & .246 \\
\hline 24 Cultural Competency II & 134 & 144 & .327 \\
\hline 25 Summative Evaluation III & 94 & 121 & .694 \\
\hline
\end{tabular}

Table 5. Pre and post test overall scores $(\mathrm{N}=312 ; \mathrm{n}=162)$

\begin{tabular}{lllll}
\hline & $\begin{array}{l}\text { Pre-test } \\
\text { mean score }\end{array}$ & $\begin{array}{l}\text { Post-test } \\
\text { mean score }\end{array}$ & Z & $\boldsymbol{p}$ \\
\hline $\begin{array}{l}\text { Name of the survey or } \\
\text { questionnaire put here }\end{array}$ & 19 & 25 & 11.10 & $<.01$ \\
\hline
\end{tabular}

\subsection{Program contact hour education evaluation}

Participants' quantitative responses on the contact hour evaluation indicated that they generally agreed or strongly agreed (75\%-95\%) that the objective was met for each module in the LCEP-ACNF. Overall ratings for program effectiveness were 4 to 5 in all categories. Table 3 provides the contact hour evaluation questions and objectives used for the LCEPACNF.

Analysis of participants' comments on the contact hour evaluation (see Table 6), revealed four themes: (1) learning new teaching strategies and ideas for clinical instruction, (2) helpfulness of workshop elements, (3) collaborating with nursing faculty from other programs, and the (4) need for collabo- 
ration/mentoring outside the workshop venue. Many participants' comments on the evaluation stated that the video vignettes used in the program were most helpful. The video vignettes which were cited as the most helpful have been placed on the QSEN.org website. Another common strength mentioned on the evaluations included the opportunity to collaborate with other nursing faculty in this workshop on managing the needs of nursing faculty, managing students' needs, and troubleshooting a variety of clinical issues. This collaboration was fostered by using breakout sessions after each module. Each workshop had different participants and listed a variety of problematic areas for troubleshooting. There was some commonality because the modules presented were the same however participants shared different stories at each workshop. Furthermore, several participants stated that they would like more opportunities to collaborate with other faculty and to learn from each other.

Table 6. Participants' categorical comments about the LCEP-ACNF workshop

\begin{tabular}{|c|c|}
\hline Category & Comment Excerpts/Summaries \\
\hline Teaching strategies & $\begin{array}{l}\text { "Giving feedback to students" } \\
\text { "Dealing with difficult students" } \\
\text { "Understanding where clinical faculty fit into the curriculum" } \\
\text { "How to send a student on observation" } \\
\text { "How to utilize SBAR communication" } \\
\text { "How to give a clinical warning to a student" } \\
\text { "How to praise a student” } \\
\text { "How to motivate a student” }\end{array}$ \\
\hline Helpfulness of workshop elements & QSEN.org. resources $>$ Videos $>$ LCEP-ACNF \\
\hline $\begin{array}{l}\text { Collaborating with nursing faculty in other } \\
\text { programs }\end{array}$ & $\begin{array}{l}\text { "Helpful to talk with faculty with similar issues from other nursing schools." } \\
\text { "Share ideas on how to support new clinical faculty." } \\
\text { "Share ideas on how to navigate hospital systems and computer access issues } \\
\text { while at clinical." }\end{array}$ \\
\hline Mentoring & $\begin{array}{l}\text { "Need for more mentoring and coaching for clinical faculty.” } \\
\text { "How seasoned faculty can support novice faculty throughout the semester." } \\
\text { "How new clinical faculty can contribute to the curriculum and offer ideas to } \\
\text { improve the clinical experience." }\end{array}$ \\
\hline
\end{tabular}

\subsection{Interview themes}

After six interviews the researcher had data saturation, where no new information was being discovered. Analysis of the interview transcripts revealed four themes: collaboration, orientation, evaluation and feedback strategies, and mentoring. Three of these themes parallel the comments from the contact hour evaluation. Each theme is presented below, with supporting excerpts from the transcripts.

All eight interviewees stated that the program gave them helpful strategies, useful tools to enhance clinical teaching, ideas to engage clinical faculty throughout the semester, and ways to further develop clinical faculty who teach adjunct or part-time in a nursing program. They also commented on the quality of the program. For example, one interviewee said, "I think that it was an excellent program; I got a lot of positive information from it. It validated a lot of things that I already thought. It also reinforced some of the weaknesses I have seen too." Another participant said,

For me I am a brand-new instructor so I hadn't even worked with any students at that point. This was perfect timing for me, because I am mostly doing clinical. For me I am finding a lot of it is very useful to me as I go along in the semester. Right now, I am doing midterm evaluations so all that information on evaluations was really helpful to me. I have actually reassessed that information recently.

One faculty member reflected on her journey into an academic position:

They hired me based on my resume. It always amazed me that they gave away the most important part of educating nursing students to someone who they really didn't know very well, and someone that they didn't provide any orientation or guidance to. It just floored me, the freedom that I had right from the beginning. ... I didn't have any guidance. Well, I guess there was one person who was helpful. But I went into 
the clinical setting all by myself without anyone to guide me or mentor me. Because what you are doing is really cool. It is really needed. The structure is needed, so that we are putting in the same amount of energy in the classroom in making sure that we have some standards, and expectation and tools to provide new faculty with. So I think what you are doing is really incredible. It is great!

\subsection{Communication with other faculty members on clin- ical teaching}

This theme captures how interviewed participants perceived the regional workshop as an opportunity to meet other nursing faculty members across the state and share their thoughts and feelings about nursing education as well as their experiences. Each interviewee said the program encouraged them to communicate better with their course coordinator, unit manager, nurses working on the unit, and their students. Interviewees recognized the value of QSEN and NOF competencies of teamwork, collaboration, and communication, particularly the need for ongoing collaboration between novice and seasoned faculty members. For example, one participant said, "Oh, I loved the program. It was helpful, I felt relieved after talking with people who had much more experience than I did." Two other participants' excerpts are below:

I think that the workshop had a lot of good and helpful points. It was nice to hear from a lot of the participants in the course, that many had a lot of the same issues with the students. So it didn't make you feel like oh no I don't want to ask a question because I will feel stupid, you know. I think everyone brought to the table something that could help them and us as well. One of the things that especially came up to me is that there is not a lot of support for adjunct faculty, 'cause I am an adjunct faculty myself.

I enjoyed hearing from other people coming from different areas and the frustrations they had sometimes as well. I think that was a common thread ... I think that validated everyone's feelings or practice on how well they think that they are doing. It isn't just us, and I think that it really identifies that there is a definite gap between people who are there full-time versus people who are adjunct.

\subsection{Orientation strategies}

The orientation process varies greatly for clinical faculty, some faculty receive a structured orientation and some receive as little as one hour of orientation but the LCEP-ACNF gave participants an opportunity to learn new strategies and tools to enhance their clinical teaching. This workshop enabled both seasoned faculty members who coordinate clinical groups and clinical adjunct faculty members who supervise students in clinical to have a standardized orientation experience that brought them together. The program content helped to streamline the orientation process and offered many examples, tools, and tips on clinical teaching. Several interviewees commented about this aspect of the workshop. For example, one said, "We don't give them... the faculty... enough orientation. I am allowed to give them 1 hour of orientation and that is eaten up just going over the syllabus and giving them the evaluations, and going over the paperwork." Another interviewee said,

And one of the things that I really loved about what you shared with us this summer was ... the idea of trying to keep the faculty members connected to what is happening on a week-by-week basis in the clinical course. So I loved your idea of every Monday morning when you sit down and send an e-mail out to the faculty to say this is the topic we are covering this week, with the links that you can make in clinical practice. That is something that is going to be fun to experiment with.

\subsection{Student clinical evaluation and feedback strategies}

One of the most important aspects of clinical teaching involves giving feedback to students through the evaluation process. The LCEP-ACNF provided materials on both formative and summative evaluation tools. The module on giving clinical feedback included video vignettes on giving a formative evaluation (a mid-point evaluation) to a student and how to identify students as star, average, and poor students. These categories clarified how to recognize and work with students in the same course at various levels. This theme emerged as a competency that novice clinical faculty greatly needed in their orientation. This theme is exemplified in three excerpts below:

... how to do your evaluations. Because I used to just go in [with] a very brief "Oh you're doing a good job. I don't see any problems." Watching your program, I really sat down with them [my students] this time and talked to them about their strengths, weaknesses. Even if I had a strong student, I still learned that you have to focus on what they can improve upon and what they are doing well. The whole part you talked about evaluating really helped me too. 
I think that the program showed me ways to engage the students ... so that you can say, "Hey, you're doing a really good job," and leave it at that. Or "You're doing a really bad job." Giving them concrete examples was really helpful. To see where they are at in their own mind and then sort of talk to them and have more of a conversation with them rather than I'm the instructor and you're the student and I'm the one in charge. The videos were helpful to show that this is a collaboration and working together and find ways to help even really good students to look for ways to get better. But helping the poor student or the middle-ground student to also find ways to improve.

The videos were wonderful in evaluating underachievers, overachievers, and your run-of-the-mill you're doing an ok job. That was great. That was helpful to me. For my first evaluations. I did like the videos; I thought that they were really well done.

\subsection{Mentorship issues for novice clinical faculty}

Each interviewee discussed the need for expert faculty to support and mentor novice faculty members during their orientation process. However, both mentees and mentors felt overwhelmed by the mentoring process given limitations of time, support, and resources from the university. Lastly, both mentors and mentees mentioned that this task would be easier if they were compensated monetarily or by reducing their workload.

During the LCEP-ACNF workshop the topic of mentorship and the role of the course coordinator was a topic at each workshop. Many course coordinators attended the workshop with their adjunct faculty and need support to mentor and support the faculty that teach adjunct in their clinical courses. The program focused on helping novice clinical faculty connect to the university environment, especially the classroom and didactic environment. Several interviewees commented on the need for mentorship as many felt that they had to learn the educator role without support from a mentor. This theme is illustrated in three excerpts below:

Just for myself being a brand new clinical instructor, I feel overwhelmed and stressed. I think the lack of mentorship that I have received as a new clinical instructor. I feel like I'm on my own teaching myself how to be a clinical instructor.

I need a mentor. I feel like I'm just going along and they're handing me papers. This is what you're going to teach and I'm hearing that with every nursing school from the faculty that it isn't going to be different at any other place. That you really don't get help.

I have found in my experience of being a hospital-based person and then coming into academia, it's interesting that my perception is the things that are really important. Like adhering to Joint Commission standards. Making sure that you're walking the walk. When I came into academia, I had a sense that my peers really were not knowledgeable about Joint Commission standards. That's an opportunity for me to double back with this new clinical person. To say this is the quick cheat sheet for the current 2016 standards. How can we make sure that the students understand how we weave these into clinical practice? You have been my mentor in QSEN. And making or looking at how we can help students understand how QSEN, how you integrate QSEN into clinical practice. Not just the words. What does it mean? What does it look like. How are nurses asked to integrate that into practice? With a new person as well as my current faculty.

\subsection{Implications for nursing education practice}

Our findings are consistent with findings on the on-line Continuing Education Program for Adjunct Clinical Nursing Faculty (LCEP-ACNF). ${ }^{[44]}$ Clinical faculty who attended or participated in both the live ${ }^{[45]}$ and on-line (LCEP-ACNF). ${ }^{[46]}$ Orientation programs showed significant improvement in pretest-posttest results. The LCEP-ACNF workshop is a first step in building competency among clinical faculty throughout the northeast region. Standardizing the orientation process for clinical faculty is a topic that is being discussed at many nursing programs, hospital facilities, and the Massachusetts Action Coalition (MAAC), a statewide coalition of nurse leaders representing practitioners, educators, and health care delivery organizations. Furthermore, because the LCEP-ACNF program had positive results when offered regionally it is likely that when disseminated nationally or internationally it will be successful. Currently, the literature does not cite a program that is offered in other countries. For this reason, the tools, videos, and other resources from the workshop are posted on line at academicclinicalfacultydevelopment.com or qsen.org, and can be incorporated into any nursing program faculty orientation around the country. The researcher can also be contacted to consult with nursing schools in other countries on how to structure an orientation 
program for their clinical faculty.

Our results support the great need to ensure that clinical faculty who teach students at the bedside are competent, able to teach safety in clinical practice, and understand the dynamic healthcare environment. The need for clinical faculty is an ongoing issue in nursing education, and the use of clinical expert nurses to work as faculty will continue to be approach to address the clinical faculty shortage. ${ }^{[1,6,8,9,50,51]}$

\subsection{Limitations}

This study had several limitations. First, participants were recruited from only one northeastern state, which may have limited the generalizability of the findings. Second, the LCEP$\mathrm{ACNF}$ was designed as an orientation program for new or novice clinical faculty in the academic role, but participants in this study were faculty members at various levels of experience. Furthermore, many participants who were interviewed had varying levels of academic experience, from never having taught clinical to having taught clinical a few semesters to having many years of clinical teaching experience. This variability may have impacted the results of the pretest-posttest scores and contact hour evaluations. However, our finding of a significant difference in the pretest-posttest scores demonstrates the need for more faculty development and support at all experience levels.

\subsection{Implications for nursing programs and dissemina- tion}

The next steps for this project are to continue offering live workshops for faculty, establish a mandatory clinical faculty program in the northeast region, and disseminate this workshop nationally. Our findings suggest that this orientation program is a success and its elements must be used to help support clinical faculty needs. The first author has engaged with representatives of QSEN whose website now has the video vignettes from the LCEP-ACNP available for all clinical faculty to use and revisit as they find necessary (see Table $1)$.

The workshop will be available for clinical coordinators to adapt as a train-the-trainer model. Developing the clinical coordinator role is imperative. The elements of this workshop can be used to support clinical faculty and encourage mentorship for those who report to a clinical coordinator in a didactic theory course. Those leading a didactic course can use many of the LCEP-ACNF elements to engage clinical faculty throughout the semester. Greater collaboration between the course coordinator and clinical faculty members will ensure continuity of principles taught between classrooms and clinical settings, of evidence-based practice from clinical teaching and theory, and more collaboration between full-time faculty and adjunct part-time clinical faculty. All these elements will enhance nursing students' education.

Our findings indicate that the greatest factor and need for clinical faculty success is a mentor. The LCEP-ACNF can be used to develop and encourage formal mentorship between faculty members and their adjunct clinical faculty partners. The next steps in this process will be ongoing continuing education and additional resources for this role. Indeed, "full-time faculty have a major responsibility to help adjunct clinical faculty members in their transition to the role of faculty member. Mentoring and supporting nurse faculty members in their roles will increase their satisfaction and have an impact on retention of existing and future nurse educators". ${ }^{45]}$ Increasing satisfaction in the workplace will greatly impact the nursing faculty shortage and retention of clinical faculty.

One idea put forth by one of our interviewees has promise for future implementation, i.e., to certify clinical instructors rather than choosing or hiring them to fill in vacant slots. As this interviewee said, "I think that if we had clinical faculty who were certified, then maybe we can hold them to a higher standard. Giving them further education, just to foster them learning more and developing more into their professional role of educator. Because many of those don't want to do anything but teach clinical."

\section{Conclusion}

The LCEP-ACNF was offered throughout Massachusetts in six workshops. This program enabled participating faculty members to meet, discuss clinical education, and learn relevant competencies a 4-hour continuing education workshop. Because participants were able to collaborate during the workshop, the adjunct faculty and clinical coordinators from individual nursing programs left the feeling connected to one another. Furthermore, the collaboration amongst nursing faculty in a regional setting allowed the participants to discover new colleagues to collaborate with. Lastly, the presenters helped to engage participants in the discussion while presenting information pertinent to the needs of clinical faculty cultivated a safe environment to share. Our qualitative and quantitative results validate the effectiveness of the LCEPACNP in supporting clinical faculty.

This project was supported through a small faculty grant and the Massachusetts Action Coalition (MAAC). This coalition, one of 51 nationwide working to implement the IOM's recommendations, ${ }^{[20]}$ is co-led by the Organization of Nurse Leaders of Massachusetts, Rhode Island, New Hampshire, and Connecticut as well as the Massachusetts Department of Higher Education. Ongoing efforts through QSEN and 
MAAC will help to sustain these efforts. The LCEP-ACNF is one way to help support novice clinical faculty to sustain the nursing faculty workforce. In the future, more research on this topic is needed to gain a better understanding of the current and future educational needs of clinical faculty. ${ }^{[52,53]}$

\section{ACKNOWLEDGements}

This study was supported by a small seed grant from the University of Massachusetts, Worcester Graduate School of Nursing and by the Massachusetts Action Coalition, a statewide coalition of nurse leaders representing practitioners, educators, and health care delivery organizations. Thank you to Dr. Jean Bouche PhD, RN, ANP-BC, AOCNP for her support on this project and data analysis.

\section{CONFlicts of InTEREST Disclosure}

The authors declare that there is no conflict of interest.

\section{REFERENCES}

[1] American Association of Colleges of Nursing (AACN). AACN's report on 2014-2015 Enrollment and Graduations in Baccalaureate and Graduate Programs in Nursing, U.S. 2015. Available from: http://www. aacn.nche.edu/research-data

[2] Gazza EA, Shellenbarger T. Successful enculturation: strategies for retaining newly hired nursing faculty. Nurse Educator. 2005; 30: 251-254. https://doi.org/10.1097/00006223-2005110 00-00009

[3] McCourt K. Learning global trends. Nursing Standard. 2011; 25(43): 64. https://doi.org/10.7748/ns.25.43.64.s56

[4] National League for Nursing, 2010. Faculty census data. Available from: http://www.nln.org/newsreleases/faculty_c ensus_092210.htm

[5] Bittner N, Bechtel C. Identifying and describing nursing faculty workload issues: a looming faculty shortage. Nursing Education Perspectives. 2017; 38(4): 171-176. PMid:28628067

[6] Tracy C, Fang D. Special survey on vacant faculty positions for academic year 2010-2011. 2010

[7] Hinder KA, Jaronsinski JM, Seldomridge LA, et al. From expert clinician to nurse educator: outcomes for a faculty academy initiative. Nurse Education Perspectives. 2016; 41(4): 194-198.

[8] Danna D, Schaubhut RM, Jones JR. From practice to education: Perspectives from three nurse leaders. Journal of Continuing Education in Nursing. 2010; 41: 83-87.

[9] National League for Nursing. Number of basic RN programs, total and by program type: 2003-2012. NLN DataViewTM. 2014. Available from: http://www.nln.org/researchgrants/slide s/pdf/AS1112_F01.pdf

[10] Candela L, Gutierrez A, Keating S. A national survey examining the professional work life of today's nursing faculty. Nurse Education Today. 2013; 33(8): 853-859.

[11] Evans JD. Factors actors influencing recruitment and retention of nurse educators reported by current nurse faculty. Journal of Professional Nursing. 2013; 29(1): 11-20. https://doi.org/10.1016/ j.profnurs . 2012.04.012

[12] Roberts KK, Chrisman SK, Flowers C. The perceived needs of nurse clinicians as they move into an adjunct clinical faculty role. Journal of Professional Nursing. 2013; 29(5): 295-301.

[13] Wyte-Lake T, Tran K, Bowman CC, et al. A systematic review of strategies to address the clinical nursing faculty shortage. Journal of Nursing Education. 2013; 52(5): 245-252. https ://doi .org/10 .3928/01484834-20130213-02

[14] Johnson KV. Improving Adjunct Nursing Instructors' Knowledge of Student Assessment in Clinical Courses. Nurse Educator. 2016; 41(2): 108-110.

Published by Sciedu Press
[15] Benner P. From novice to expert: Excellence and power in clinical nursing practice. (Commemorative ed.). Upper Saddle River, NJ: Prentice Hall Health. 2001.

[16] Benner P. Using the Dreyfus model of skill acquisition to describe and interpret skill acquisition and clinical judgment in nursing practice and education. Bulletin of Science, Technology \& Society. 2004; 24: 188-189. https://doi .org/10.1177/0270467604265061

[17] Moreland JE. What prevents nurses from entering faculty positions early in their professional career: A qualitative study (Doctoral dissertation). 2011.

[18] Brown T, Sorrell J. Challenges of novice nurse educator's transition from practice to classroom. Teaching and Learning in Nursing. 2017; 12: 207-211. https://doi.org/10.1016/j.teln.2017. 03.002

[19] Benner P, Sutphen M, Leonard V, et al. Educating nurses: A call for radical transformation. San Francisco: Jossey-Bass; 2010.

[20] Institute of Medicine. The future of nursing: Leading change, advancing health. Washington, DC: National Academies Press; 2011.

[21] Koharchik L, Jakub K. Starting a job as adjunct clinical instructor American Journal of Nursing. 2014; 114(8): 56-60.

[22] Reid TP, Hinderer KA, Jarosinski JM, et al. Expert clinician to clinical teacher: Developing a faculty academy and mentoring initiative. Nurse Education in Practice. 2013; 13: 288-292. PMid:23615037 https://doi.org/10.1016/j.nepr.2013.03.022

[23] Boswell C, Cannon S. Overview of evidence-based practice. In S. Cannon \& C. Boswell (Eds.), Evidence-based teaching in nursing: A foundation for educators. Sudbury, MA: Jones \& Bartlett Learning.

[24] Kalb KA, O'Conner-Von SK, Brockway C, et al. Evidence-based teaching practice in nursing education: Faculty perspectives and practices. Nursing Education Perspectives. 2015; 36(4): 212-219.

[25] Schwartz BM, Gurung RAR. Evidence-based teaching for higher education. Washington, DC: American Psychological Association. 2012

[26] Schaar GL, Titzer JL, Beckham R. Onboarding new adjunct clinical nursing faculty using a quality and safety education for nurses-based orientation model. Journal of Nursing Education. 2015; 54(2): 111-5.

[27] Bauer TN, Erdogan B. Outcomes of organizational socialization In C. R. Wanberg (Ed)., The Oxford handbook of organizational socialization. New York, NY: Oxford University Press; 2012.

[28] Graybill JO, Carpenter MH, Offord Jr J, et al. Employee onboarding: Identification of best practices in ACRL libraries. Library Management. 2013; 34(3): 200-218.

[29] Klein HJ, Polin B. Are organizations on board with best practices onboarding? In C. R. Wanberg (Ed.), The Oxford handbook of organizational socialization. New York, NY: Oxford University Press; 2012. $267-287 \mathrm{p}$ 
[30] Ellis A, Bauer T, Erdogan B. New-employee organizational socialization. In J.E. Grusec \& P.D. Hastings (Eds.), Handbook of socialization: Theory and research. New York: The Guilford Press; 2015.

[31] Baker SL. Nurse educator orientation: Professional development that promotes retention. Journal of Continuing Education in Nursing. 2010; 41: 413-417. PMid:20506931 https://doi.org/10.3928/ 00220124-20100503-02

[32] Lin S, Chiang H, Chen I. Comparing nurses' intent to leave or stay: Differences of practice environment perceptions. Nursing \& Health Sciences. 2011; 13(4): 463-467. https://doi.org/10.1111/j . 1442-2018.2011.00640.x

[33] Kalisch B, Lee H, Rochman M. Nursing staff teamwork and job satisfaction. Journal of Nursing Management. 2010; 18(8): 938-947. https://doi.org/10.1111/j.1365-2834.2010.01153.x

[34] Boev C. The relationship between nurses' perception of work environment and patient satisfaction in adult critical care. Journal of Nursing Scholarship. 2012; 44(4): 368-375. https : //doi .org/10 $.1111 / j .1547-5069.2012 .01466 . x$

[35] Bohan P, Laing M. Can leadership behavior affect quality and safety? British Journal of Healthcare Management. 2012; 18(4): 184-190.

[36] Brunetto Y, Farr-Wharton R, Shacklock K. Supervisor-subordinate communication relationships, role ambiguity, autonomy and affective commitment for nurses. Contemporary Nurse. 2011; 39(2): 227-239.

[37] Tervo-Heikkinen T, Kiviniemi V, Partanen P, et al. Nurse staffing levels and nursing outcomes: A Bayesian analysis of Finnishregistered nurse survey data. Journal of Nursing Management. 2009; 17(8): 986-993. https://doi.org/10.1111/j.1365-2834.20 $09.01020 . \mathrm{x}$

[38] Institute of Medicine. Keeping patients safe: Transforming the work environment of nurses. Washington, DC: National Academies Press; 2004.

[39] Davis NL, Davis DA, Rayburn WF. Clinical faculty: taking the leading teaching quality improvement and patient safety. American Journal of Obstetrics in Gynecology. 2014; 211(3): 215.

[40] Rytterström P, Cedersund E, Arman M. Care and caring culture as experienced by nurses working in different care environments: A phenomenological-hermeneutic study. International Journal of Nurs- ing Studies. 2009; 46(5): 689-698. 2009. https://doi.org/10.1 016/j.ijnurstu.2008.12.005

[41] Hewitt P, Lewallen LP. Ready, set, teach! How to transform the clinical nurse expert into the part-time clinical nurse educator. Journal of Continuing Education in Nursing. 2010; 41: 403-407.

[42] Kowalski K, Horner M, Carroll K, et al. Nursing clinical faculty revisited: The benefits of developing staff nurses as clinical scholars. Journal of Continuing Education in Nursing. 2007; 38: 69-75.

[43] Silver K. Development and preliminary testing of an on-line continuing education program for adjunct clinical faculty. International Journal of Nursing. 2014; 1(2): 07-21.

[44] Silver K, Manning K. Live continuing education program for adjunct clinical nursing faculty. CEU Evaluations on Pilot Study. 2016.

[45] Kitpatrick DL. Evaluating programs: the four levels. 2nd ed. San Francisco, CA: Berrett-Koehler Publishers; 1998.

[46] National League for Nursing. Nurse Educator Core Comptency. 2012. Available from: http://www.nln.org/professional-d evelopment-programs/competencies-for-nursing-educa tion/nurse-educator-core-competency

[47] Quality and Safety in Nursing Education. 2007.

[48] Cronenwett L, Sherwood G, Pohl J, et al. Quality and safety education for advanced nursing practice. Nursing Outlook. 2009; 57(6): 338348. https://doi.org/10.1016/j.outlook.2009.07.009

[49] Massachusetts Department of Education. Nurse of the future: Nursing core competencies. 2010.

[50] Silver Dunker K. Manning K. Live continuing education program for adjunct clinical nursing faculty. Nursing Education Perspectives. 2018; 39(1): 16-18. https ://doi.org/10.1097/01. NEP.00000 00000000248

[51] DeSantis KL. Perceptions of teaching effectiveness of part-time and full-time clinical nursing faculty of BSN education (Doctoral dissertation). 2012.

[52] American Association of Colleges of Nursing (AACN). Special survey on vacant faculty positions. 2011.

[53] Suplee PD, Gardner M, Jerome-D’Emilia B. Nursing faculty preparedness for clinical teaching. Journal of Nursing Education. 2014; 53(3): 38-41. 